\title{
On a Karmic Management Approach to Push Forward a Large Project
}

\author{
Wei-Cheng Cui ${ }^{1,2 *}$ \\ ${ }^{1}$ School of Engineering, Westlake University, China \\ ${ }^{2}$ Shanghai Engineering Research Center of Hadal Science and Technology, Shanghai Ocean University, China
}

Submission: February 21, 2019; Published: March 05, 2019

${ }^{*}$ Corresponding author: Weicheng Cui, Chair professor at Westlake University, China and adjunct professor at Shanghai Ocean University, China

\section{Abstract}

To act as a project leader to manage a large research or engineering project is a dream for many researchers. Traditionally only those with administration power can get the chance to be project leader and it may take him a long time to obtain the funding from governmental agency. In this paper, the author will introduce a karmic management approach for an ordinary researcher how to push forward a large project if he really has the dream. This approach has been practiced by the author in the last six years and reasonably validated.

Keywords: Large project; Karmic Management Approach; Funding; Technology

\section{Introduction}

To act as a project leader to manage a large research or engineering project is a dream for many researchers. In parallel to the "three-storey building" metaphor proposed by Feng [1] who described a perfect human life is similar as climbing a three-storey building, I propose here a three-stage metaphor for a perfect researcher. Feng's first floor is the material life represented by money owned, the second floor is the spiritual life represented by the level one reached in science or art and the third floor is the soul life represented by the level one reached in philosophy and religion [1]. My first stage is one's ability to use a computer to do his own research, the second stage is his ability to use the administration power he obtained to manage a team to finish a large project and the third stage is his ability to use his personality and reputation to manage a team to finish a large project. The karmic management approach presented in this paper is especially addressed to those researchers who wish to reach the third stage.

Basically, the project leader needs to solve two issues, one is to obtain the enough funding and the other is to lead a team to solve all the technical issues. For a large project, the funding required is high and if the project is in the frontier of science and technology, the technical issues are also very challenging. It is a big problem for a potential project leader how to solve these two issues. In this paper, the author will introduce a karmic management approach for an ordinary researcher how to push forward a large project if he really has the dream. This approach has been practiced by the author in the last six years and reasonable success has been achieved.

\section{The Karmic Management Approach}

The characteristics of a large project is its high cost and complex technology. It needs a team of many people to work together. Traditionally, a researcher needs to be promoted to a higher position and then he has the chance to lead a group. The opportunity to be promoted to a higher position is by ability and sometimes by chance. Only few positions are available. The project leader needs to apply for the funding for the large project from governmental agencies. This could take many years to persuade the governmental agency to grant the funding. For example, it took us 10 years from 1992 to 2002 to persuade the Ministry of Science and Technology (MOST) of Chinese government to sponsor the "Jiaolong" deep manned submersible project and another 10 years to finish the development work of the deep manned submersible [2].

The governmental funding only covered the submersible but not the mothership. Without a specific mothership, the sea trials and future applications are impossible to be carried out. It took us another 10 years from 2005 to 2015 to obtain the funding for constructing a specific mothership and this ship should be put into service in 2019. In order to carry out the sea trials and initial period of applications, an old ship named "Xiangyanghong 09" was converted to a temporary mothership [3] and this ship supported the "Jiaolong" dives from 2009 to 2017. This added a lot of difficulties and risks in the sea trials and initial applications. This experience is the main reason to motivate this author to explore other approaches and until one day in 2013, I got the book 
"Karmic Management" [4], I thought I have found the method and decided to put it into practice. That is the main reason why I call my approach the karmic management approach.

If a researcher has a good idea, he needs the money and his team to start his project immediately, otherwise, this problem may be solved by others first. The conventional approach hardly considers this time factor. In many cases, when the researcher starts his project after the funding received, the idea is already out of date. So, the first step of this karmic management approach is to start your project immediately when you think it is worth doing. The first thing you need to do is to consider how much resources you have and then you contribute all of them out. The more the better. This is the key for the success of this karmic management approach. This is equivalent to the venture capital fund if someone needs to start a company or it is a bait if you go on fishing. This shows your determination and confidence to your project and it is very important for the future support you receive from the society. If you cannot persuade your family members to support you, it means that this new approach is not suitable for you and you can still use the traditional approach.

The second step is to figure out the project target and estimate how much money and personnel to be needed for completing it. This can be done with a system thinking described in the General Systems Theory (GST) [5]. It is important to have a clear definition of your project target and scope, then you can make an estimation how many people and how much money you need to complete the project within you planned period.

The third step is to cut the funding cake into small pieces and figure out which piece suits which potential funding resource. You can seek support from your organization, your local government and your central government. For some pieces, it may be hard to be applied from the governmental resources, then you can seek the support from private sectors. One is the investment and the other is the donation. In order to get the donation from society, your own donation is an important indicator. For the investment, what you need is a cooperation partner since you are not interested in other things except to finish your project as soon as possible. If you oversee the company yourself, very soon you may move away from the original project since other investors' interest is of a higher priority than your original project. What they concern is how much money you make for them rather than whether your dream has realized. You must be aware of the fact.

The fourth step is to turn your dream into his dream by applying the Karmic Management theory [4]. Basically, the Karmic Management theory states that you will achieve success hundred percent if you strictly follow the eight-step method described in that reference. This method is also a summary of three authors' own experience. Please refer to the book for the detailed theory. From my understanding, the essence is to adapt yourself from a small Self to a big Self shown in (Figure 1) [4].

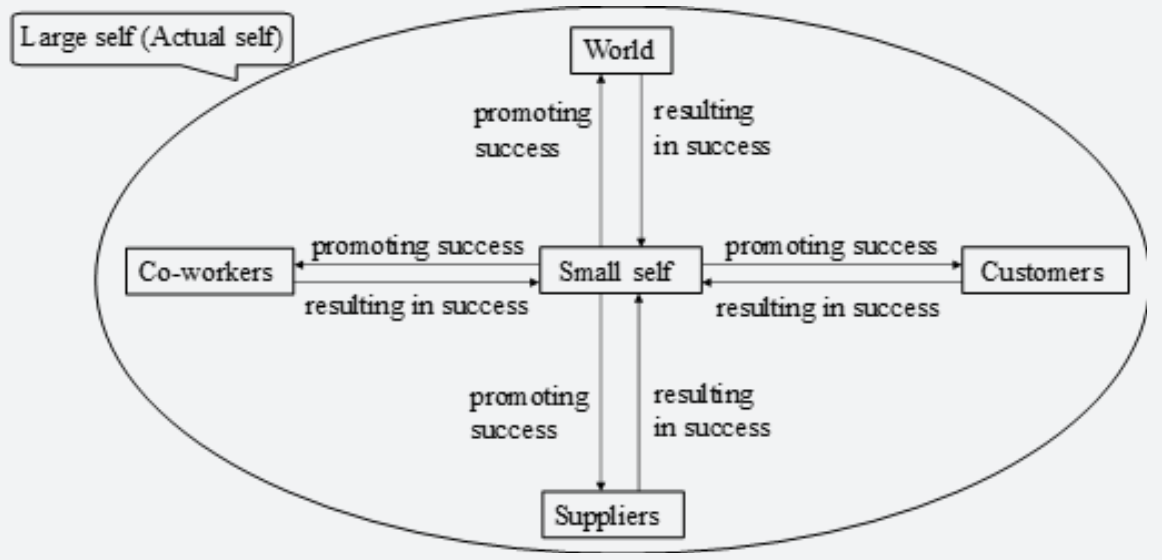

Figure 1: Two selfes diagram

According to this theory, you act as a mother of four children, one is your colleagues (or co-workers), one is your suppliers, one is your customers, and the last is the whole world. For you to successfully complete your project, you need to make them success. The essence of this approach is to use the power of love to solve all the problems occurred in the cooperation process. Since you have made it very clear that the completion of this project will be more beneficial to your four children, so they will be more care about the project success than you. This could mostly attract the support from the four children. As a project leader, you should never complain anybody or anything since complain does not solve any problem. Second, you should never have the idea to fire someone in your group. If you find one of your colleagues could not finish his duties in time, one simple method is to reduce his working load and move it to others in the team or recruiting another person. You can reduce his salary since his task is reduced based on the principle of justice and equity. If he thinks the salary is too low in your team and he wants to resign, then you can let him go. This has a much better effect on other colleagues than you fire one colleague.

The fifth step is to progress your project like rolling a snowball. The key sticking force is your personality (karmic force). You start your project with the support from family members and then you 
may get supports from friends and then enlarge to friend's friends. Using this approach, basically you can obtain whatever resources you need. So, the key point in this step is your confidence on success. You should believe that this project will succeed if you do not give it up. It only depends on you, the project leader, and not on others. Your confidence and persistence are the main sticking force to make the snowball larger and larger.

The six step is thanksgiving. You need to appreciate any help you received from others such as colleagues, customers, suppliers and the world. Thanksgiving has great karmic force and it is also a key for the success of this approach. You must do all the time when you meet the people or speak to the public. In order to improve the reliability that you fulfil your project within the planned time period, you may apply the redundancy principle in both the funding and technical issues. If you think that person A can finish his work within the time frame is only $80 \%$, then if you recruit another person B to work on the same problem, if this person's success rate is also $80 \%$, then your success rate to solve that issue will be upgraded to $0.96(\mathrm{P}(\mathrm{AUB})=\mathrm{P}(\mathrm{A})+\mathrm{P}(\mathrm{B})-\mathrm{P}(\mathrm{A}) \mathrm{P}(\mathrm{B})$ if we assume $\mathrm{A}$ and $\mathrm{B}$ are independent).

So, the procedure of this karmic management approach can be summarized into six steps:

a. Action immediately;

b. Decomposition by system thinking;

c. To cut the cake into pieces for fund raising;

d. To turn your dream into his dream according to Karmic Management theory;

e. To roll the snowball based on your own personality;

f. Thanksgiving.

\section{A Practical Demonstration}

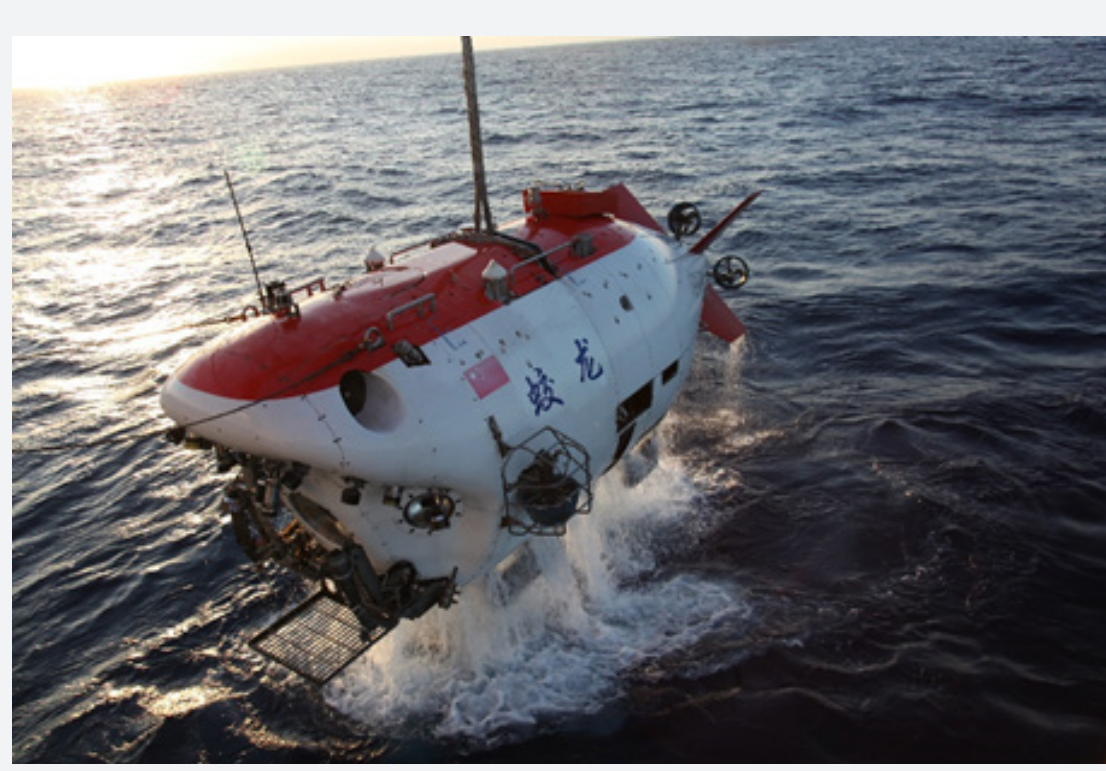

Figure 2: 7000m human occupied vehicle "Jiaolong".

First, I would like to address where was my dream from. In 2002, I was appointed as the project leader for the development of 7000 m deep human occupied vehicle (HOV) "Jiaolong” as shown in (Figure 2). The previous history in China was only about $300 \mathrm{~m}$ and that manned submersible named "7103" was developed by another team [6]. We could not access the research reports of that project. At that time our team is very incomplete and lack many personnel. No one in our team had seen a real HOV before. So many difficulties were met at the beginning. I recruited many fresh students to join the team. We invited experts to give lectures to our team and to assess and make comments to our design. Through this process, in 2012 we have successfully completed the $7000 \mathrm{~m}$ sea trials [2,3] and this project was assessed a great success by MOST. This experience let me know that actual technology challenge is not a problem and the personnel is not a problem.
The key to the success of a large project is the management. If someone trusted me and provided me enough funding, I have the confidence to finish any large project since I have grasped the key points in the management process. I urgently need another chance to examine this point of view.

In 2011 during the $5000 \mathrm{~m}$ sea trial period of Jiaolong submersible, I followed a lecture by Dr. Ding Kang who is an ocean scientist, he told us the importance of hadal science and due to lack of equipment, Chinese ocean scientists cannot access the hadal trenches and this field was an empty in China. He appealed the MOST to sponsor a cruise to use Jiaolong to investigate the hadal trenches whose depths are from $6000 \mathrm{~m}$ to $11000 \mathrm{~m}$. I was aware if Chinese ocean scientists really want to do investigation on hadal trenches, the depth capability of Jiaolong is not adequate 
and we need to develop immediately the manned/unmanned submersibles for full ocean depth (FOD).

Secondly, I was aware that the MOST will not start the FOD submersibles because they have already funded the $4500 \mathrm{~m}$ class submersibles (one AUV, one ROV and one HOV). The FOD submersibles need to be started after we finished the $4500 \mathrm{~m}$ class submersibles. I was the project leader of $4500 \mathrm{~m} \mathrm{HOV}$. It is clear to me that at least another 5 years are needed to complete the $4500 \mathrm{~m}$ HOV project.

Thirdly, the main reason we decided the target of $7000 \mathrm{~m}$ for Jiaolong was that we wanted to be the No.1 in the world since in 2002 the deepest HOV was Shinkin6500 which is of $6500 \mathrm{~m}$ depth. However, in 2012 just before our 7000m sea trials, movie director James Cameron took his privately built one-man submersible 10,898 m down to the Challenger Deep in the Pacific Ocean's Mariana Trench (http:// www. deepseachallenge.com/). There are several organizations also working on the development of three-person operational manned submersibles. It was told that Japan started the consideration to develop Shinkai12000. In the United States, Taylor and Lawson [7] presented their research on the development of the three-person operational FOD HOV "Deep search" and the Triton company has presented a similar conceptual design "Triton $36000 / 3$ " on their website. So, the competition was quite intensive then and if we do not act quickly, we will lose that competition.

However, it was obvious if I stay in my original organization, I cannot do it immediately since all the team has to do the development of $4500 \mathrm{~m}$ HOV. Based on my analysis, if I resign and recommend one of my colleagues to be the project leader, he is also capable enough to lead that project. So, I seriously consider the success rate if I resign from this post and seek the support of another organization to start the development of FOD HOV immediately after I finish the Jiaolong project. Based on the analysis of my own resources I think it is more than $70 \%$. So, I decided to take the risk to do it.

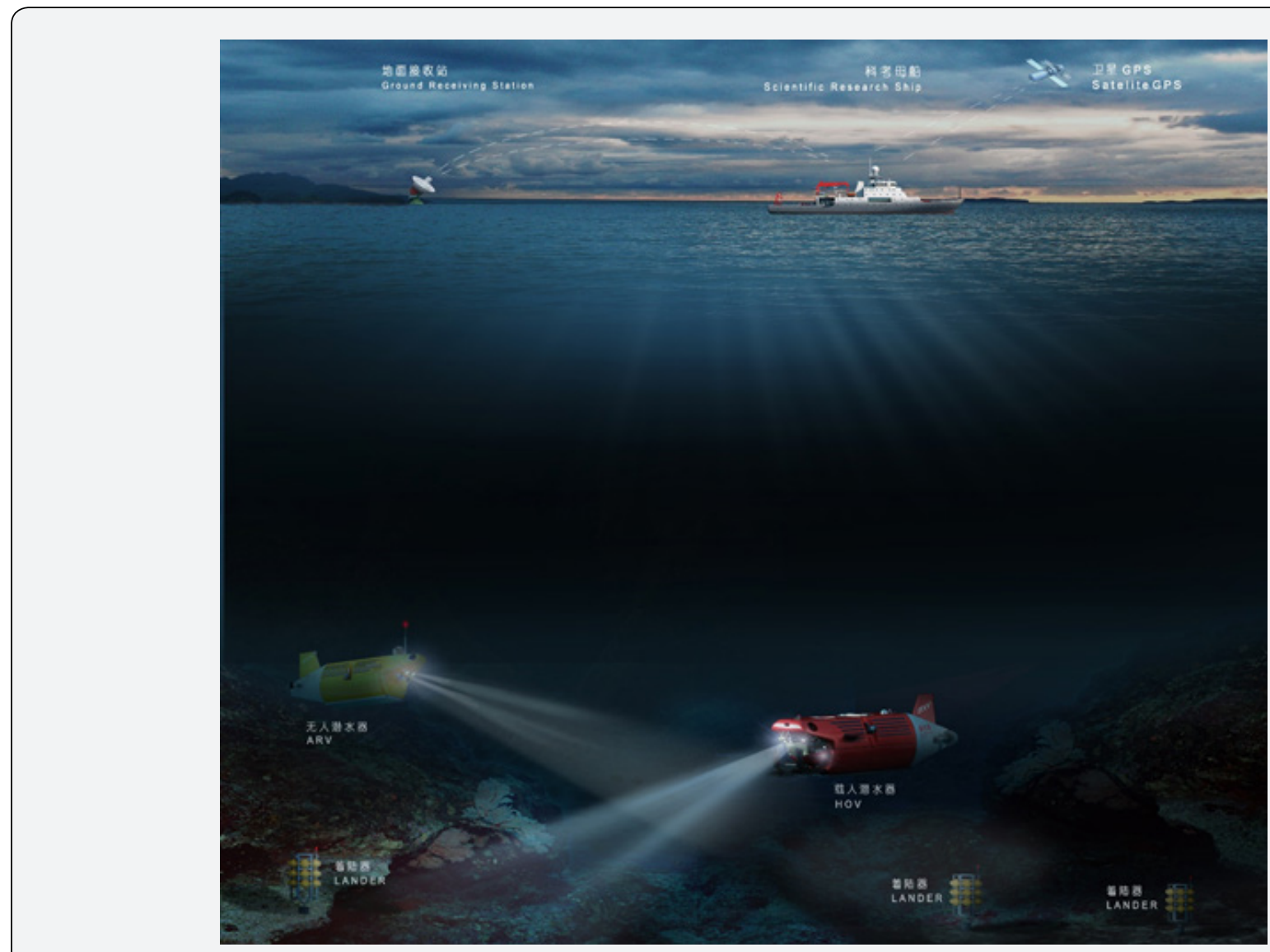

Figure 3: A simple illustration of the basic components for the movable laboratory for hadal trenches.

The first step was to seek the support from my family. I was fully aware that my wife will be strongly against this "crazy" idea since in my previous research center, I was the deputy director and I oversaw the deepsea research field. After the success of Jiaolong project, this field will be full of projects and I do not need to worry about anything. I will have a lot of honors due to my contribution to the Jiaolong project. So, I started to seek the support from my son who was a 15 years old boy. One night just before I was on board the ship to do the $7000 \mathrm{~m}$ sea trials for Jiaolong, I had a serious talk to my son. I told him after the success of the $7000 \mathrm{~m}$ sea trials of Jiaolong, I had two options, one is to stay in the original organization to oversee the development of $4500 \mathrm{~m} \mathrm{HOV}$ and the other is to seek the support from another organization to do the $11000 \mathrm{~m}$ HOV. I know your mum will be against my second option, 
if you are against it, I will give it up. After a while of thinking, my son told me he will support me if I do not do any bad things to the society. With his support, I know I can choose the second option now since I have two votes against one.

I drafted my resignation report during the period of $7000 \mathrm{~m}$ sea trials and submitted immediately after we finished the sea trials. After the resignation of the deputy director was approved, I contacted four potential universities and finally decided to join Shanghai Ocean University (SHOU) to set up a new research center called Hadal Science and Technology Research Center (HAST) with a focus on the development of a movable laboratory for hadal trenches.

The second step is to figure out the project target and estimate how much money and personnel to be needed for completing it. Although my actual interest is the development of FOD HOV, and this is NO. 1 stuff in the world. However, for the use by scientists, it should be a complete system.

A manned submersible poses a risk for those in the vehicle. In deciding whether Jiaolong should carry out manned sea trials, some administrative officers in charge of the Jiaolong project were against it because there were no rescue facilities in China at that time. So, an unmanned submersible was required before the manned submersible. Both manned and unmanned submersibles cannot work very long time on the bottom of the ocean, but landers can be left on the bottom for longer periods. For all those facilities to work, a dedicated mothership is necessary. Thus, although our initial target was to develop a FOD HOV, the final design of the new project ultimately included three landers (light-, mediumand heavy- payload), one FOD unmanned submersible (hybrid autonomous and remotely operated vehicle (ARV), one FOD HOV and a dedicated mothership of 4800-ton displacement. I call the whole system as a movable laboratory for hadal trenches (Figure 3). The basic rationale and concepts for the comprehensive investigation system and the preliminary designs of FOD landers, ARV and HOV have been described in Cui et al. [8].

The benefits of the movable laboratory can be summarized as follows. As is well-known, the highest cost for the use of submersibles is the ship time. The movable laboratory can produce an optimal economic performance because researchers can carry out an ocean survey with the mothership no matter day or night. When the movable laboratory arrives to a new area, the ARV will carry out a wide area exploration first to determine the focused research area and the basic marine parameters of the area. Then three baited landers will be deployed to collect fish and other fauna samples, to take water and sediment samples or to capture pictures via video cameras.

Finally, the HOV will be sent down to complete the fine and complex operations and sampling using manipulators. During the day, the landers, ARV and HOV can work collaboratively. At night, the landers and ARV can still be used for the sea floor survey. From the technical development point of view, this can greatly reduce the risk of HOV development and application. This is due to the following two factors. (1) Both landers and the ARV can be regarded as the test platforms for some key technologies of the HOV except for their independent functions since most of the equipment used in landers and the ARV are used in the HOV. (2) During the sea trials and its future applications of the HOV, the ARV can be used as a rescue means or a test recording means which can video the navigational and operational performances of the HOV near the sea bottom.

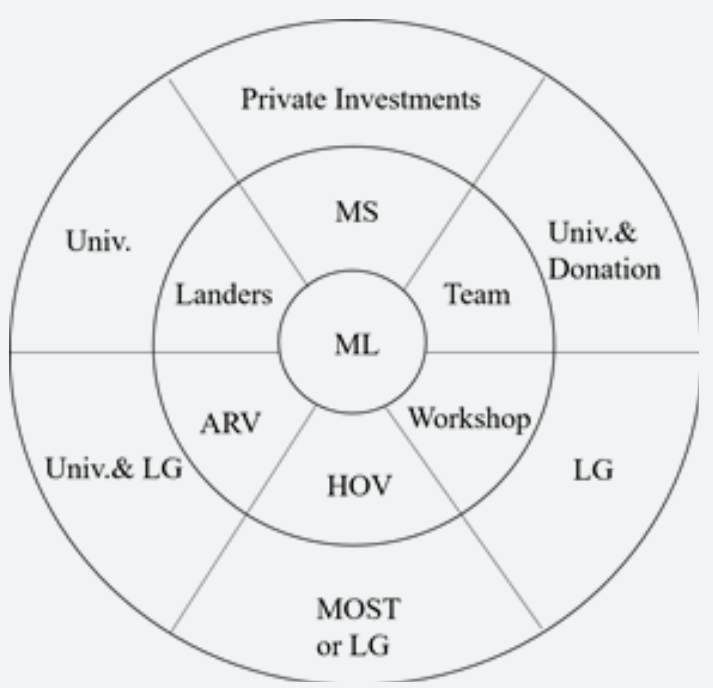

Figure 4: Schematic diagram for cutting a funding cake into pieces (ML: Movable Laboratory, MS: Mothership, ARV: Autonomous \& Remotely Operated Vehicle, HOV: Human Occupied Vehicle, LG: Local Government).

I planned to spend 10 years (2013-2023) just before my retirement to finish the project. The concept is very attractive, but it needs a lot of money. So now I come to the third step. I cut the funding cake into small pieces as shown in (Figure 4) and figure out which piece suits which potential funding resource. There are six things I need to do to finish the project. The first is to recruit the team members. I am fully aware that with the university salary level of SHOU, I cannot recruit the personnel I need. So, I 
persuaded my son and my wife first to take out all our saving in the past which is $2 \mathrm{M} \mathrm{RMB}$, then I wrote to one of my classmates who was a millionaire to ask whether he could make some donation and he promised to donate the same amount as me. Then I speak to my sister who also owned a small company and she promised to donate $1 \mathrm{M}$. My two brothers also made some donations based on their economic conditions.

So, before I formally joined SHOU, I have already got more than 5 M RMB which is enough for me to apply for a formal foundation and can support my team for a couple of years as a supplement of extra salary. With this condition, I only spent about two months to finish the recruit with initial 10 members. Our team started the design of the $11000 \mathrm{~m} \mathrm{HOV}$. After another two months we have finished the preliminary conceptual design of the HOV and identified all the key technologies we need to solve in order to develop the FOD HOV. Then I broke the team into two, one is to develop three FOD landers and the other is to develop FOD ARV. SHOU together with the local government provided the funding to buy the equipment. After that I started to seek the funding for the mothership. Here I applied the Karmic Management theory [4].

Instead of asking someone for help, I published an article in September 18, 2013 in Wenhui Daily and said if someone has the ship, I can give him my three landers and one ARV. Many private businessmen came to me to inquire what is the condition to have my landers and ARV. After I contacted them and discussed with them, one businessman (Mr. L) realized what I need is a new ship and no existing ship can meet my requirement for the HOV operation. He could make the investment if I can persuade the university president to pay $30 \%$. I spoke to the university president and he told me that the University do not have such an amount of money. Then I went for another friend (Mr. W) to ask him for cooperation. Mr. W did his Ph.D. with me in the same group in University of Bristol at the same time and after that he worked in foreign companies while I worked in research institute. He owned a small company at that time.

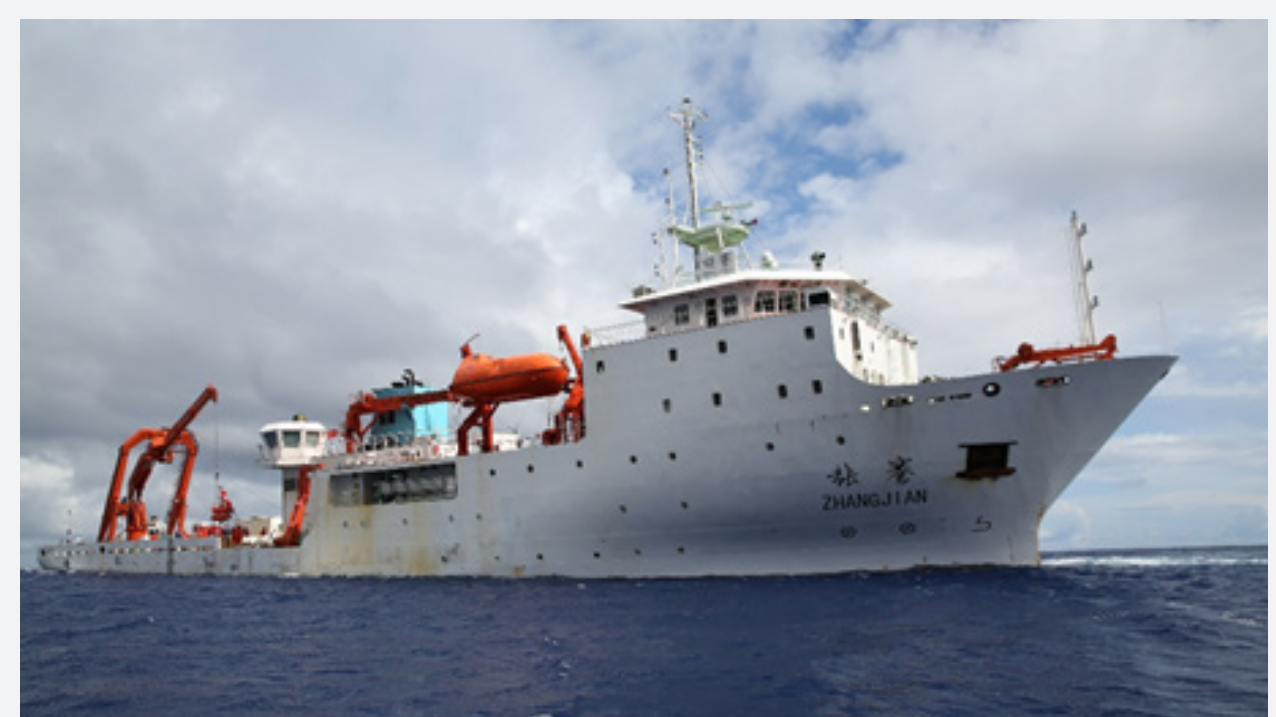

Figure 5: 4800-ton displacement research vessel "Zhang Jian".

The challenging question I asked him is whether he has earned enough money to support his family after twenty year's hard work. He was certainly yes as far as I knew. So, I asked him the second question whether he could cooperate with me for another ten years and if we finish the project I figured out, we could be national heroes since I received a title of this from the Jiaolong's project. He was very interested to this venture and got full support from his family. So, he registered the Shanghai Rainbowfish Ocean Technology Co. Ltd (ROFT) and signed a strategic cooperation agreement with SHOU to jointly develop the movable laboratory. I know he himself do not have such an amount of money for the mothership. I just asked him to sign the contract with the main investor, Mr. L. L paid 70\% and we paid the 30\%. After we signed the contract, then we divided our amount of $30 \%$ into 10 pieces, we ask 10 friends of ours to buy our share, so through that method, we spent about 4 months to get enough funding and $\mathrm{Mr}$.
$\mathrm{L}$ was responsible for the design and construction of the specific mothership. The specific mothership named "Zhang Jian" shown in (Figure 5) was put into service in July 2016. The lucky enough thing is that another institute can supply all the ship equipment with a later payment, so we used the saved money to build another small research vessel "Shen Kuo" shown in (Figure 6). $\mathrm{Mr} \mathrm{L}$ registered another company to operate these two research vessels.

As my design team's work is going, the next task is to have a building for the assembly. If using the traditional approach, many years may be needed to get funding for constructing a specific building in the campus. Furthermore, due to the move of the campus, SHOU owed bank a big loan and the university was not allowed to construct any new buildings before they paid back the loan. So, I turned my eyesight to the local government. In order to attract the investment, many local governments can build the 


\section{Annals of Social Sciences \& Management studies}

workshop and rend it to the enterprise. The Lingang High-tech Park was just on the design stage when I promised to join them, they were willing to make a specific design for my workshop.
The building named "Shutong Building" shown in (Figure 7) was handed to us for use in January 2016.

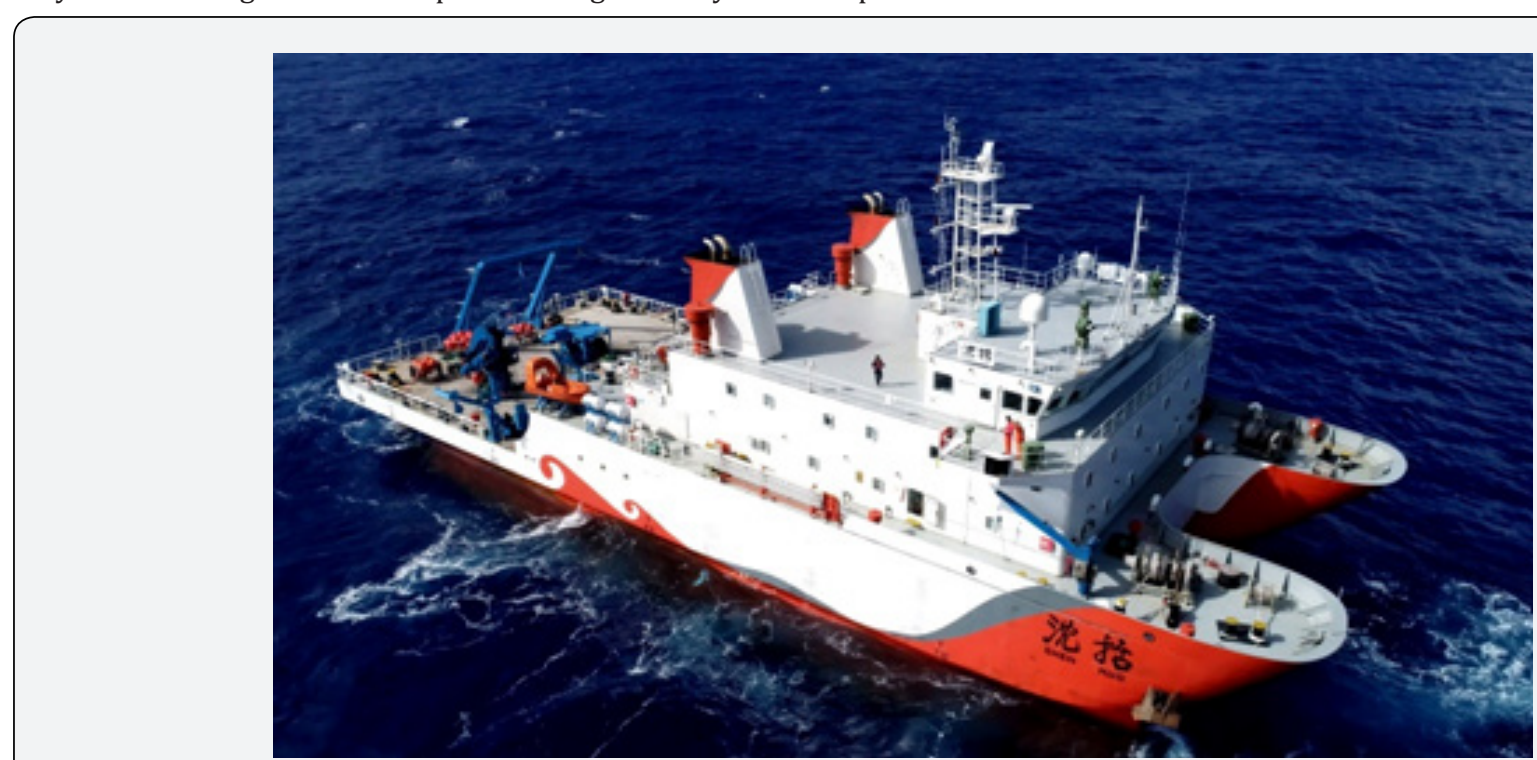

Figure 6: 2200-ton displacement SWATH type research vessel "Shen Kuo".
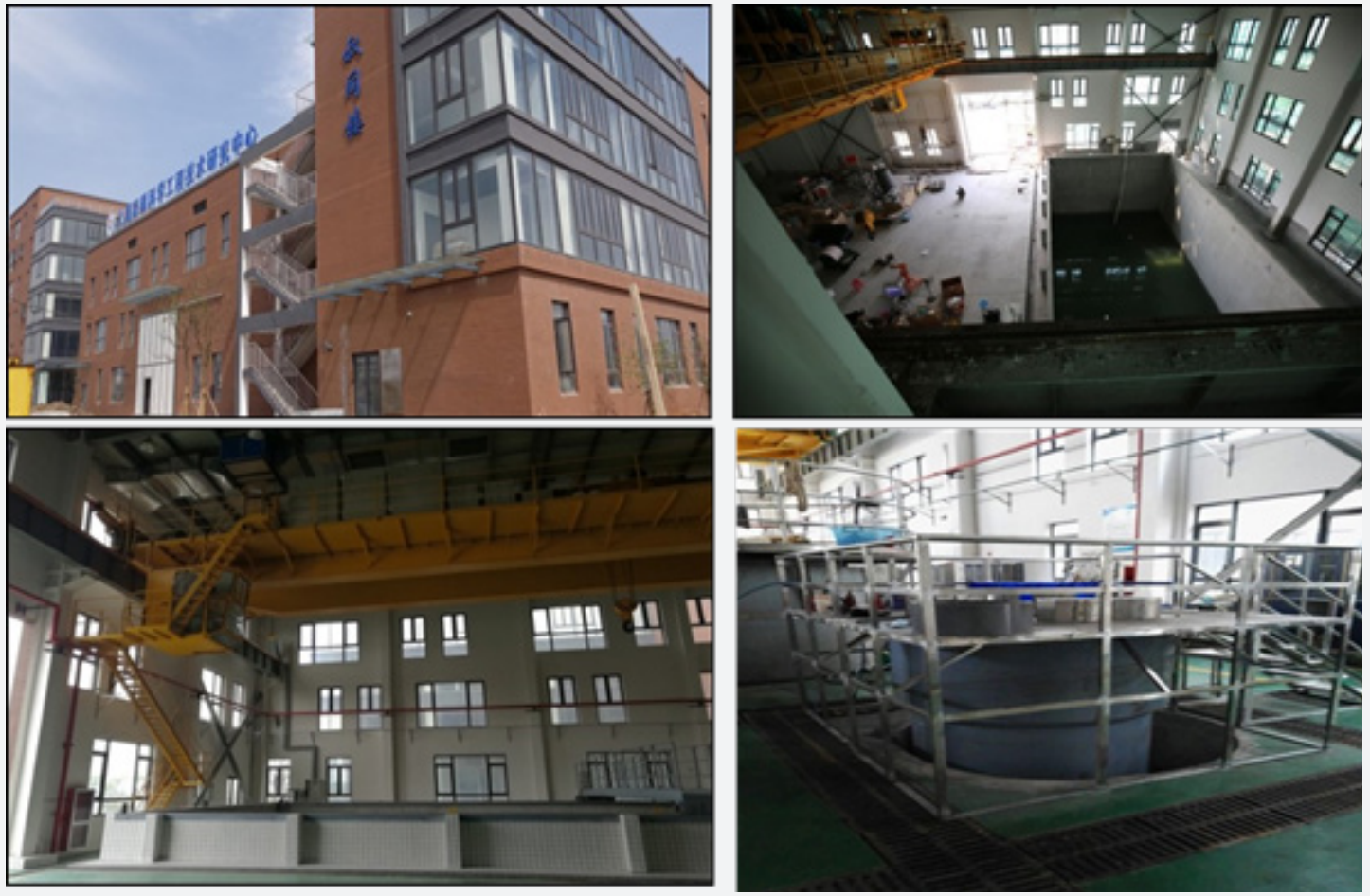

Figure 7: "Shutong building" for the assembly of submersibles. Its total space is $2600 \mathrm{~m} 2$, it has a crane with a capacity of 30 tons, a small open water tank with a size of $20 \mathrm{~m}$ (length) $\times 10 \mathrm{~m}$ (width) $\times 7 \mathrm{~m}$ (depth) and four pressure chambers whose maximum test pressure from 140 $\mathrm{MPa}$ to $180 \mathrm{MPa}$.

The FOD HOV is left for support from MOST. We finished the prototype of a FOD lander and ARV in September and had a 4000m class sea trials in October 2015. This success and fast speed showed by this novel approach won some support from Department of Science and Technology of Shanghai Municipal government. They sponsored two projects to let our team to continue the work. In December 2016 to Feb 2017, we finished three landers and ARV and had another cruise to the Marina trench for $11000 \mathrm{~m}$ sea trials and New Britain trench for scientific investigation. Three landers have successfully reached the Challenger Deep while ARV 
met some problem and stopped in $6300 \mathrm{~m}$. (Figure 8) showed the first phase of the movable laboratory finished in Dec 2016. The main reason why ARV did not reach the Challenger Deep was not due to the technical difficulty but the worldview and the trust between persons. For my team to focus on the research I gave up my potential share in Rainbowfish company and I also did not allow my team members to own any share from the Rainbowfish company. This is certainly different from governmental policy. As ROFT developed very quickly under the leadership of Mr. W, the project leader for ARV felt unhappy and he thought I might play a deceit to our team members with Mr. W.

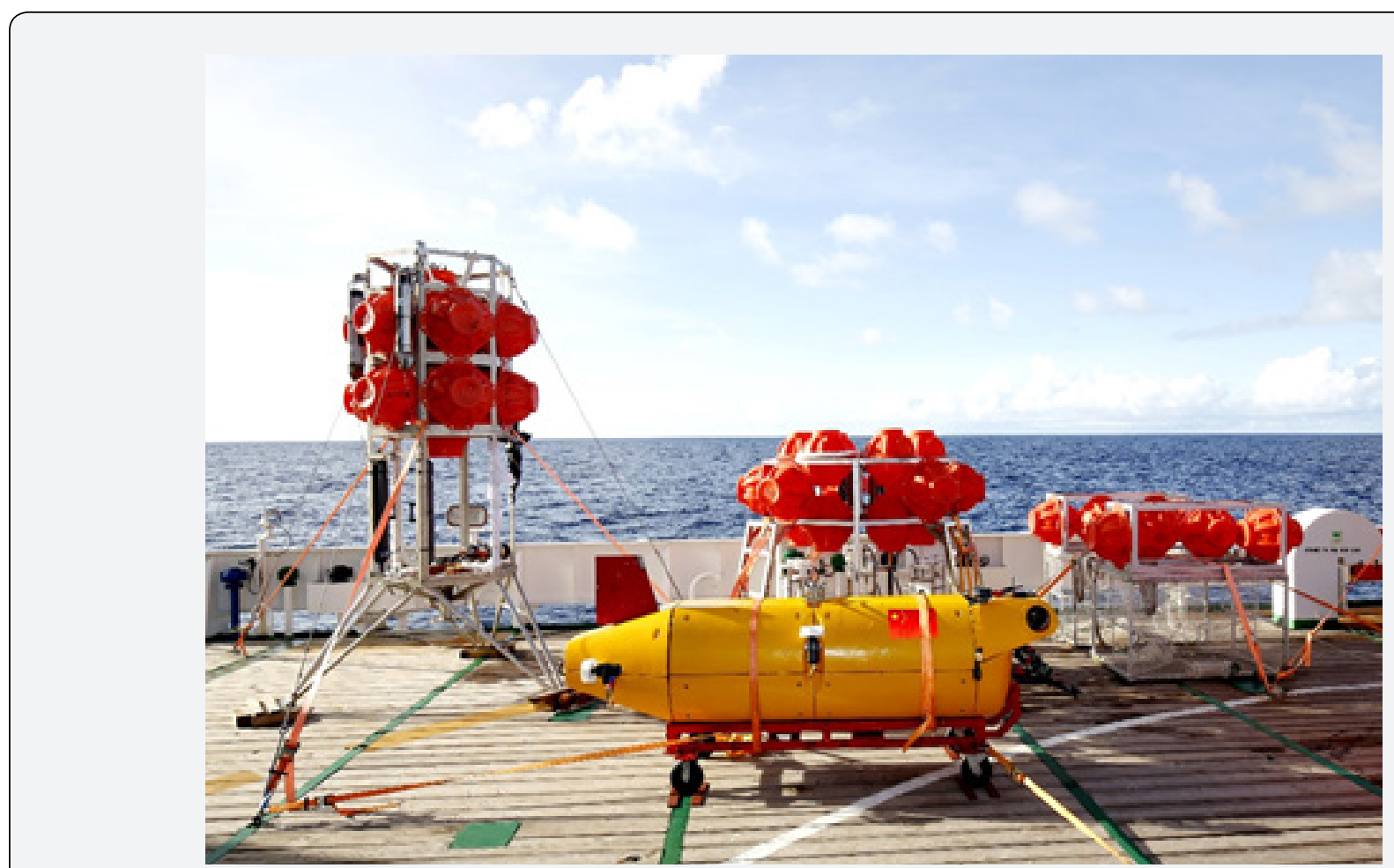

Figure 8: The first phase of the movable laboratory completed in Dec.2016 (three FOD landers and one FOD ARV prototype).

Another thing was that although my initial intention was to have my previous organization in cooperation with SHOU to speed up the development process of the FOD HOV. However, my resignation made the leadership unhappy and we became the competitors afterwards. In 2016 March, MOST had really sponsored the FOD HOV project and my team lost the competition to my previous organization. This made quite some of my team members losing the confidence to continue the development of FOD HOV.

With these two factors, after the success of $4000 \mathrm{~m}$ sea trials, the ARV project leader spent some time secretly to cooperate with another person to start their own company. Since he spent quite some time in his private business, and this also affected the other members. So, the laboratory tests in 2016 for ARV were inadequate for the $11000 \mathrm{~m}$ sea trials and this led directly to the failure. After the cruise, he was left the team due to the difference in the worldview.

Due to the loss of the competition, Shanghai Municipal government also stopped their support after 2017. It was very easy for me to stop the project. After discussing with the leaders of SHOU and Mr. W of ROFT, we decided to continue the project by applying the principle of rolling a snowball. We can seek the support from other local governments such as neibouring Zhejiang Province or Shenzhen. In order to attract their attention, we need to speak an even bigger story. So, since March 2017, I let my team working on the design of FOD HOV while Mr. W and me were contacting other potential funding resources with the new target of one practical $11000 \mathrm{~m}$ ARV, a $6000 \mathrm{~m} \mathrm{HOV}$, a $11000 \mathrm{~m}$ HOV and several tourist submersibles.

Since January 2018, we let our original team in HAST working on the $11000 \mathrm{~m}$ ARV project, formed another team within ROFT to carry out the design of $6000 \mathrm{~m} \mathrm{HOV}$ and we also successfully persuaded Mr. C to join the ROFT in charge of the capital operation and preparing RFOT for share market. Mr. W successfully expanded his company to Zhoushan, Zhejiang province. I was successfully persuaded Westlake University to support this project. So now our current plan is to finish the development of $11000 \mathrm{~m}$ ARV and $6000 \mathrm{~m} \mathrm{HOV}$ in 2020 and $11000 \mathrm{~m} \mathrm{HOV}$ in 2023. Under the background of Yangtze River Delta Integration, we can apply for funding both from Shanghai municipal government and Zhejiang provincial government, RFOT has a much better condition to attract the private investment compared with its initial period, I am very confident that we can fulfil our target. Of course, during the management process, I also applied the thanksgiving principle 
to increase the karmic power and the redundancy principle to improve the reliability. However, the redundancy level will also depend on the funding you obtained. So, through this approach, you will find that all the difficulties of a large project will be reduced to just one problem, the funding issue.

More importantly, what I have found through my practice is that the actual cost for this project using this approach is just $1 / 3$ $\sim 1 / 2$ of the traditional approach fully sponsored by governments. The ratio of self-donation to total donation we received is about $1 / 4$, and the ratio of governmental support funding to private investment funding is also about $1 / 4$. So, through this approach, it can save a lot of governmental expenditure for the same project target. Although due to my personal limitation which cannot win the full trust from my team members and some problems occurred in the past six years, through this practice, it is basically proved from positive and negative sides that the Karmic Management theory [4] is correct. This theory can help many people to realize their dreams.

\section{Conclusion}

In this paper, a novel approach based on the Karmic Management theory to push forward a large project based on individual's resource is introduced. This approach has been partially practiced by the author in the past six years and it is validated from both positive and negative sides. The author strongly believe that this approach can help many people to realize their dreams.

\section{Acknowledgement}

This work was supported by the State Key Program of National Natural Science of China "Structural Reliability Analysis on the Spherical Hull of Deepsea Manned Submersibles" (Grant
No. 51439004), the "Construction of a Leading Innovation Team" project by the Hangzhou Municipal government, the Startup funding of New-joined PI of Westlake University with grant number (041030150118). The project was received support from many sources and friends in the past six years. I am particularly grateful to my cooperation partner, Dr. Xin Wu, Mr. Yunjun Lu and Mr. Weibing Cao for their persistence to go ahead with me. Ms. Jinyu Sha helped me to draw and (Figures $1 \& 4$ ), her help is also appreciated.

\section{References}

1. Feng, Zikai (1990) I with master Hongyi, in Collection of Works of Feng Zikai, Zhejiang Literature and Art Publishing House, Hangzhou (in Chinese), China.

2. Cui WC (2013) Development of the Jiaolong Deep Manned Submersible. Marine Technology Society Journal 47(3): 37-54.

3. Cui WC, Liu, F, Hu, et al. (2013) On 7000m Sea Trials of the Manned Submersible "JIAOLONG". Marine Technology Society Journal 47(1): 67-82.

4. Roach, M, McNally, C, Gordon, et al. (2009) Karmic Management: What Goes Around Comes Around in Your Business and Your Life. Published by Doubleday Religion, an imprint of the Crown Publishing Group, a division of Random House, Inc., New York, USA.

5. Chen, David, Stroup, Walter (1993) General System Theory: Toward a Conceptual Framework for Science and Technology Education for All. Journal of Science Education and Technology 2(3): 447-459.

6. Cui, W.C. (2018) An Overview of Submersible Research and Development in China. Journal of Marine Science and Application 17(4): 459-470.

7. Taylor, L, Lawson, $T$ (2009) Project Deepsearch: An Innovative Solution for Accessing the Oceans[J]. Marine Technology Society Journal 43(5): 169-177.

8. Cui, W.C., Hu, Y, Guo, et al. (2014) A preliminary design of a movable laboratory for hadal trenches. Methods in Oceanography 9: 1-16.

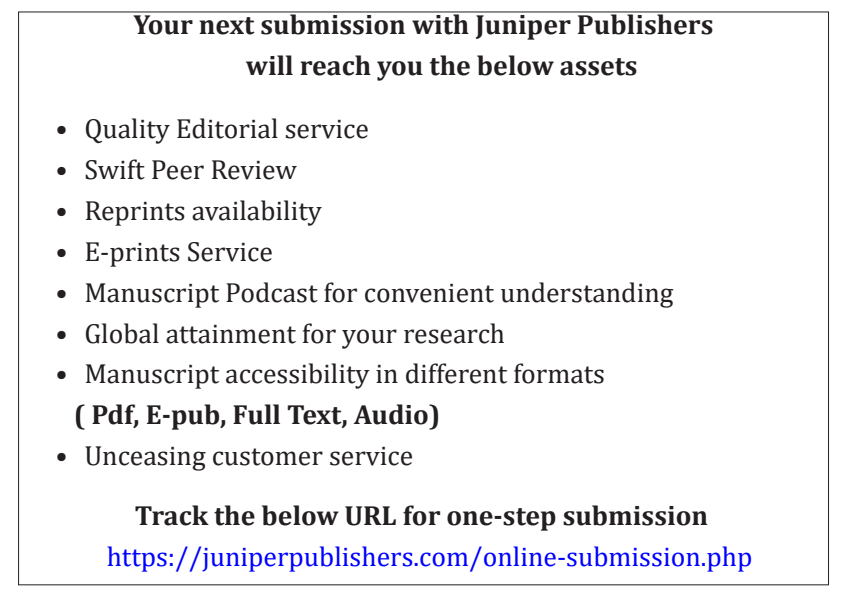

